\begin{abstract}
Iranica
Abstracta Iranica Revue bibliographique pour le domaine irano-aryen

Volume 42-43 | 2021

Comptes rendus des publications de 2019-2020
\end{abstract}

\title{
Nigora D. Dvurechenskaja. « К ВоПРОсУ О СЕВЕРНОЙ ГРАНИЦЕ БАКТРИИ »
}

Johanna Lhuillier

\section{(2) OpenEdition Journals}

\section{Édition électronique}

URL : https://journals.openedition.org/abstractairanica/52223

DOI : 10.4000/abstractairanica.52223

ISSN : 1961-960X

Éditeur :

CNRS (UMR 7528 Mondes iraniens et indiens), Éditions de l'IFRI

\section{Référence électronique}

Johanna Lhuillier, « Nigora D. Dvurechenskaja. « K Вопросу о Северной Границе Бактрии » », Abstracta Iranica [En ligne], Volume 42-43 | 2021, document 2, mis en ligne le 15 avril 2021, consulté le 28 décembre 2022. URL : http://journals.openedition.org/abstractairanica/52223 ; DOI : https:// doi.org/10.4000/abstractairanica.52223

Ce document a été généré automatiquement le 28 décembre 2022.

Tous droits réservés 


\title{
Nigora D. Dvurechenskaja. « K ВОПРОСУ О СЕВЕРНОЙ ГРАНИЦЕ БАКТРИИ 》
}

\author{
Johanna Lhuillier
}

\section{RÉFÉRENCE}

Nigora D. Dvurechenskaja. « К ВОПРОСУ о СЕВЕРНОЙ ГРАНИЦЕ БАКТРИИ » [К voprosi o Severnoj granitse Baktrii = Sur la question de la frontière nord de la Bactriane] in Archil Balakhvantsev, Nikolai Makkaveev (eds.). The Age of Empires. Eastern Iran from The Achaemenids to The Sasanians: Archaeology, History, Culture. Proceedings of the International Scholarly Conference Dedicated to the Memory of Boris Anatolevich Litvinsky, Moscow, April 1618, 2018. Moscou, 2019, p. 99-113.

1 L'article de N.D. Dvurechenskja vise à inscrire les résultats de plusieurs années de fouille sur la forteresse hellénistique d'Uzundara, près de Baysun dans le sud de l'Ouzbékistan, dans un débat plus vaste qui porte sur l'emplacement de la frontière entre Sogdiane et Bactriane lors de la période hellénistique. Parmi les chercheurs travaillant sur cette période (notamment E. Rtveladze, Cl. Rapin, L. Stančo, I. P’jankov), deux hypothèses principales s'affrontent, plaçant la frontière soit dans cette même région de Baysun dans le nord de la province du Surkhan-Darya, soit dans le sud de celle-ci sur le fleuve Amou-Darya.

2 Pour l'auteur, qui est également responsable des fouilles à Uzundara, cette forteresse avait pour fonction principale dès sa construction lors de la fin du $4^{\mathrm{e}} \mathrm{s}$. - début du $3^{\mathrm{e}} \mathrm{s}$. av. n.è. de protéger la frontière bactro-sogdienne des invasions de nomades situés des côtés nord et nord-ouest, tout en permettant de s'assurer le contrôle de la population locale, rôles qu'elle a conservés lors de la période gréco-bactrienne. C'est là selon elle une confirmation du rôle du réseau de forteresses qui parcourt la région, et dont fait 
partie Uzundara, comme système de fortification à la frontière entre Sogdiane et Bactriane.

\section{AUTEURS}

JOHANNA LHUILLIER

UMR 5133 CNRS-Université de Lyon 